\section{RMD Open}

Rheumatic \& Musculoskeletal Diseases

\title{
Diabetes mellitus and cardiovascular
} risk management in patients with rheumatoid arthritis: an international audit

Anne Grete Semb (D) , ${ }^{1}$ Silvia Rollefstad, ${ }^{1}$ Eirik Ikdahl, ${ }^{1}$ Grunde Wibetoe, ${ }^{1}$ Joseph Sexton, ${ }^{2}$ Cindy Crowson, ${ }^{3}$ Piet van Riel, ${ }^{4}$ George Kitas, ${ }^{5}$ Ian Graham, ${ }^{6}$ Solbritt Rantapää-Dahlqvist, ${ }^{7}$ George Athanasios Karpouzas (D) ,8 Elena Myasoedova, ${ }^{9}$ Miguel A Gonzalez-Gay (D) , ${ }^{10}$ Petros P Sfikakis, ${ }^{11}$ Maria G Tektonidou (D. ,11 Argyro Lazarini, ${ }^{12}$ Dimitrios Vassilopoulos, ${ }^{12}$ Bindee Kuriya, ${ }^{13}$ Carol Hitchon, ${ }^{14}$ Maria Simona Stoenoiu, ${ }^{15}$ Patrick Durez (D) , ${ }^{15}$ Virginia Pascual-Ramos (D) , ${ }^{16}$ Dionicio Angel Galarza-Delgado (D) , ${ }^{17}$ Pompilio Faggiano, ${ }^{18}$ Durga Prasanna Misra (D) , ${ }^{19}$ Andrew A Borg, ${ }^{20}$ Rong Mu, ${ }^{21}$ Erkin M Mirrakhimov, ${ }^{22}$ Diane Gheta, ${ }^{23}$ Karen Douglas, ${ }^{5}$ Vikas Agarwal (D) ${ }^{19}$ Svetlana Myasoedova, ${ }^{24}$ Lev Krougly, ${ }^{25}$ Tatiana Valentinovna Popkova (D) , ${ }^{26}$ Alena Tuchyňová, ${ }^{27}$ Michal Tomcik, ${ }^{28}$ Michal Vrablik, ${ }^{29}$ Jiri Lastuvka, ${ }^{30,31}$ Pavel Horak, ${ }^{32}$ Helena Kaspar Medkova, ${ }^{33}$ Anne M Kerola, ${ }^{1}$ SURF-RA collaborators

To cite: Semb AG, Rollefstad S, Ikdahl E, et al. Diabetes mellitus and cardiovascular risk management in patients with rheumatoid arthritis: an international audit. RMD Open 2021;7:e001724. doi:10.1136/ rmdopen-2021-001724

- Additional supplemental material is published online only. To view, please visit the journal online (http://dx.doi.org/10. 1136/rmdopen-2021-001724).

Received 4 May 2021 Accepted 20 June 2021

Check for updates

(c) Author(s) (or their employer(s)) 2021. Re-use permitted under CC BY-NC. No commercial re-use. See rights and permissions. Published by BMJ.

For numbered affiliations see end of article.

Correspondence to Dr Anne Grete Semb; a-semb@diakonsyk.no

\section{ABSTRACT}

Aim The objective was to examine the prevalence of atherosclerotic cardiovascular disease (ASCVD) and its risk factors among patients with RA with diabetes mellitus (RA$\mathrm{DM}$ ) and patients with RA without diabetes mellitus (RAwoDM), and to evaluate lipid and blood pressure (BP) goal attainment in RA-DM and RAwoDM in primary and secondary prevention. Methods The cohort was derived from the Survey of Cardiovascular Disease Risk Factors in Patients with Rheumatoid Arthritis from 53 centres/19 countries/3 continents during 2014-2019. We evaluated the prevalence of cardiovascular disease (CVD) among RA-DM and RAwoDM. The study population was divided into those with and without ASCVD, and within these groups we compared risk factors and CVD preventive treatment between RA-DM and RAwoDM.

Results The study population comprised of 10543 patients with RA, of whom 1381 (13\%) had DM. ASCVD was present in $26.7 \%$ in RA-DM compared with $11.6 \%$ RAwoDM $(p<0.001)$. The proportion of patients with a diagnosis of hypertension, hyperlipidaemia and use of lipid-lowering or antihypertensive agents was higher among RA-DM than RAwoDM $(p<0.001$ for all). The majority of patients with ASCVD did not reach the lipid goal of low-density lipoprotein cholesterol $<1.8 \mathrm{mmol} / \mathrm{L}$. The lipid goal attainment was statistically and clinically significantly higher in RA-DM compared with RAwoDM both for patients with and without ASCVD. The systolic BP target of $<140 \mathrm{~mm}$ $\mathrm{Hg}$ was reached by the majority of patients, and there were no statistically nor clinically significant differences in attainment of $\mathrm{BP}$ targets between RA-DM and RAwoDM.

Conclusion CVD preventive medication use and prevalence of ASCVD were higher in RA-DM than in RAwoDM, and lipid goals were also more frequently obtained in RA-DM. Lessons

\section{Key messages}

What is already known about this subject?

- Clinical audits as the Survey of Cardiovascular Disease Risk Factors in Patients with Rheumatoid Arthritis can be applied to monitor data recording and management, measure clinical performance against guideline standards and inform appropriate treatments to improve quality of care in routine practice.

- Both patients with rheumatoid arthritis (RA) and diabetes mellitus (DM) are associated with a doubled risk of atherosclerotic cardiovascular disease (ASCVD) compared with the general population.

What does this study add?

- The diagnosis of hypertension and hyperlipidaemia was more common among patients with RA with DM than patients with RA without DM.

- Among patients with RA with DM, the prevalence of ASCVD was doubled compared with patients with RA without DM.

- Appropriate preventive cardiovascular disease (CVD) medication was more widely used and lipid targets more often obtained among patients with RA with DM compared with those without DM.

How might this impact on clinical practice or further developments?

- Lessons may be drawn from CVD prevention programmes in DM to benefit patients with RA. 
may be learnt from CVD prevention programmes in DM to clinically benefit patients with $R A$.

\section{INTRODUCTION}

The prevalence of diabetes mellitus (DM) is approximately $9 \%$ of the world's adult population, although there are large geographical variations from as low as $2.5 \%$ (Republic of Moldovia) to $17 \%$ (Egypt). ${ }^{12}$ Furthermore, related to physical inactivity, unhealthy diet and obesity, the prevalence of diabetes is increasing in all age groups. The increased risk of cardiovascular disease (CVD) in patients with DM is well recognised, and there are specific guidelines for CVD prevention and risk factor management in such patients. ${ }^{3}$

Rheumatoid arthritis (RA) is the most common inflammatory rheumatic disease and is, like DM, associated with increased risk of CVD which is not fully explained by traditional CVD risk factors. ${ }^{4-6}$ This increased risk in patients with RA may be comparable to that of patients with $\mathrm{DM}^{7}$ Prevention of atherosclerotic cardiovascular disease (ASCVD) in patients with RA is advocated both by the European League Against Rheumatism ${ }^{8}$ and other recent recommendations. ${ }^{4}$ Despite these efforts, ASCVD prevention in patients with RA was noted to be incomplete across the world in our international audit, Survey of Cardiovascular Disease Risk Factors in Patients with Rheumatoid Arthritis (SURF-RA), ${ }^{9}$ which was motivated by the clinical experience of inadequate CVD risk factor recording and CVD preventive medication use among patients with RA in many countries.

Patients with RA have a high comorbidity burden, and one of the most common comorbidities in RA is DM. ${ }^{10}$ Compared with the general population, the prevalence of DM among patients with RA seems to be increased, ${ }^{11}$ although there are conflicting reports. ${ }^{11-15}$ The increased risk of type $2 \mathrm{DM}$ (T2DM) may be due to lifestyle-related factors such as physical inactivity and overweight, but also related to glucocorticoid use. Concomitant DM among patients with RA is a problem, because these patients have more ASCVD, depression, renal failure and hospital stays compared with patients with RA without DM. ${ }^{16}$ In patients having both RA and DM, the risk of CVD is nearly tripled. ${ }^{7}$

Little is known about how DM affects ASCVD risk factor screening and management in patients with RA. Our objective was to examine the prevalence of ASCVD and its risk factors in patients with RA with and without $\mathrm{DM}$, and to evaluate their lipid and blood pressure (BP) goal attainment in primary and secondary prevention based on the results from the large international audit SURF-RA.

\section{METHODS}

The data in SURF-RA were derived from already established clinical cohorts, as well as from prospective recording in cardiology and rheumatology clinics, between 2014 and 2019. Patients aged $\geq 18$ years with clinically diagnosed RA were eligible for inclusion. Participating centres were divided into Western Europe, Eastern Europe, North America and Asia.

The following RA-related variables were recorded: rheumatoid factor and anti-citrullinated protein antibody positivity, inflammatory markers including $\mathrm{C}$ reactive protein (CRP) and erythrocyte sedimentation rate (ESR), use of antirheumatic medication, as well as Disease Activity Score using 28 joints with ESR. CRP, ESR and lipid values were analysed according to each centre's laboratory standards.

The presence of self-reported established CVDs, including coronary heart disease (CHD), stroke, peripheral arterial disease, atrial fibrillation and heart failure were registered by the physician in the data collection sheet. The following self-reported risk factors of CVD: smoking, physical activity, known diagnoses of hypertension, hyperlipidaemia and DM, as well as the most recent CVD risk factor measurements including BP, weight, height and waist circumference, were also recorded in the data collection sheet. Lipids, glucose and glycosylated haemoglobin A1c (HbAlc) were recorded if there were measurements within 1 year of examination. We lacked information on fasting status prior to lipid measurements, and both fasting and non-fasting lipid values may have been included. For general CVD risk screening, fasting status has been shown not to influence the prognostic value of blood lipids. ${ }^{17}$ The use of lipid-lowering agents, antihypertensive treatment and anti-diabetic medication was recorded. Glucose levels or HbAlc were not included in the DM definition, since the rationale was to identify only cases in which DM had been diagnosed and thus necessary preventive measures should have been taken.

The treatment goal of antihypertensive treatment was set at $<140 / 90 \mathrm{~mm} \mathrm{Hg}$ for patients without $\mathrm{DM}$ and $<140 / 80 \mathrm{~mm} \mathrm{Hg}$ for patients with DM according to the prevailing guidelines at the time of the survey.

At the time of the survey, the European Society of Cardiology recommended that low-density lipoprotein cholesterol (LDL-c) goal should be $\leq 2.5 \mathrm{mmol} / \mathrm{L}$ for patients at high risk of CVD and $\leq 1.8 \mathrm{mmol} / \mathrm{L}$ for patients with established ASCVD. ${ }^{18}$

To reflect primary and secondary CVD prevention, comparisons of CVD risk factors and their management between patients with RA with and without DM were made separately for those with and without ASCVD (CHD, stroke or peripheral artery disease). To evaluate BP and LDL-c target attainment in primary prevention, we compared patients with RA with and without DM and without known ASCVD but who were using lipid-lowering or antihypertensive medications.

Summary statistics are presented as means or medians, with SD or IQR. To compare independent samples for continuous variables, we used Mann-Whitney $\mathrm{U}$ test, and for categorical variables, the $\chi^{2}$ test was applied. Data handling and statistical analyses were performed with R V.4.0.3 (R Foundation for Statistical Computing, Vienna, Austria). 


\section{RESULTS}

Of the total SURF-RA cohort $(\mathrm{n}=14504)$, we included cases with no missing data on age, sex, presence of DM or ASCVD. Cases with no recorded diagnosis of DM but recorded use of insulin or oral antidiabetic medication were excluded $(n=83)$. The total study cohort comprised 10543 individuals from 19 countries across three continents. The proportion of patients from different world regions and ethnic groups is shown in table 1. RA-related factors and use of antirheumatic medication are shown in online supplemental table 1 .

In most countries, $8 \%-15 \%$ of patients with RA had concomitant DM (figure 1). A total of $27 \%$ of the patients with RA with DM had ASCVD compared with $12 \%$ of patients with RA without DM (figure 2). CHD, stroke, peripheral artery disease, atrial fibrillation or heart failure were all more common among patients with RA with DM compared with patients with RA without DM. The total study population was divided into those with a diagnosis of ASCVD ( $\mathrm{n}=1434)$ and those without $(\mathrm{n}=9109)$.

\section{Patients with RA without ASCVD}

Among the patients with RA without ASCVD, there were 1012 cases who had concomitant DM and 8097 cases who did not. There were no differences in sex distribution, but patients with DM were slightly older than those without DM (table 1). The most common type of DM was T2DM $(91.4 \%)$, while 49 patients $(4.8 \%)$ had type $1 \mathrm{DM}$ and 38 (3.8\%) had no record of DM type. Only $386(38.1 \%)$ of patients with RA with DM had a measurement of HbA1c within 1 year before the survey inclusion (median (IQR) HbA1c 50 (42-61) $\mathrm{mmol} / \mathrm{mol}$ ) (table 2). Among the patients classified as not having DM, only 1179 (14.6\%) had a measurement of HbAlc within the previous year, and a small proportion of them had elevated HbAlc as a sign of either impaired glucose regulation with $\mathrm{HbAlc}$ of $42-47 \mathrm{mmol} / \mathrm{mol}(\mathrm{n}=100)$ or undiagnosed DM with HbAlc $48 \mathrm{mmol} / \mathrm{mol}$ or higher $(\mathrm{n}=17)$.

The proportion of patients with a diagnosis of hypertension, hyperlipidaemia, use of lipid-lowering or antihypertensive agents was higher among patients with RA with DM than among those without (table 1). Patients with RA with DM had on average higher body mass index (BMI) and they were less often moderately or more than moderately physically active than those without DM (table 2). Patients with RA with DM were less frequently current smokers than patients with RA without DM (13\% vs 17\%).

Lipid measurements were available in $65 \%$ of the patients with DM and in $55 \%$ of patients without DM (table 2). Levels of LDL-c, high-density lipoprotein cholesterol (HDL-c) and total cholesterol were lower in the DM group, whereas triglycerides were higher compared with patients with RA without DM. Overall, patients with RA with DM and without ASCVD, but on lipid-lowering treatment for primary prevention purposes had lower LDL-c compared with patients without DM, and this difference was statistically significant in subpopulations from Western Europe, Eastern Europe and North America (figure 3A).
BP measurements were available for $77 \%$ of the patients with RA with DM and $70 \%$ of the patients with RA without DM (table 2). Systolic BP was slightly higher among patients with RA with DM compared with those without (median difference $5 \mathrm{~mm} \mathrm{Hg}$ ), whereas diastolic BP was lower. We also compared systolic BP of patients with RA with and without DM receiving antihypertensive medication (figure $3 \mathrm{C}$ ), and observed no significant differences.

\section{Patients with RA with ASCVD}

Of the patients with RA with ASCVD, 369 had concomitant DM and 1065 did not. There were no significant differences in age, sex or distribution across world regions in patients with ASCVD with and without DM (table 1). Of the patients with RA with DM, 352 (95.4\%) had T2DM, $12(3.3 \%)$ had type $1 \mathrm{DM}$ and $5(1.4 \%)$ unknown type. Only $46.3 \%$ had a measurement of HbAlc within 1 year prior to survey inclusion (median (IQR) HbAlc of 49 (42-58) $\mathrm{mmol} / \mathrm{mol}$ ) (table 2). Of the patients classified as not having DM, only $13.3 \%$ had a HbAlc measurement within a year, and there were 21 cases with $\mathrm{HbAlc}$ of $42-47 \mathrm{mmol} / \mathrm{mol}$ and 3 cases with $\mathrm{HbAlc}$ above the diabetic threshold $(48 \mathrm{mmol} / \mathrm{mol}$ or higher). Of ASCVD subtypes, $\mathrm{CHD} /$ stroke/peripheral artery disease was present among $61.0 \% / 19.2 \% / 51.2 \%$ of the patients with RA with DM versus $53.5 \% / 22.2 \% / 44.4 \%$ of the patients without DM, respectively (figure 2 ).

Proportions of patients with a diagnosis of hypertension, diagnosis of hyperlipidaemia and use of lipid-lowering or antihypertensive drugs including beta-blockers and ACEinhibitors/angiotensin receptor blockers were higher for the patients with RA with ASCVD and DM compared with those without DM (table 1). Of note, of the patients with RA with ASCVD but no DM compared with patients with RA with ASCVD and DM, only 53\% versus 72\% respectively reported use of statins. Patients with RA with ASCVD and DM had higher BMI than patients without DM (table 2). There were no significant differences in physical activity level or smoking status.

Lipid measurements were available in $73 \%$ of patients with DM and in $65 \%$ of patients without DM with ASCVD (table 2). Comparable to the data on patients without ASCVD, levels of LDL-c, HDL-c and total cholesterol were lower whereas triglycerides were higher among those with DM compared with those without. Overall, neither the majority of patients with RA with ASCVD with DM nor without DM reached the treatment target of LDL-c $<1.8 \mathrm{mmol} / \mathrm{L}$ in any of the world regions (figure 3B). On average, LDL-c levels were closest to the treatment target in North America and highest in Eastern Europe. Overall, patients with DM had lower LDL-c compared with patients without DM, and the difference was statistically significant in subpopulations from North America, Eastern and Western Europe (figure 3B).

BP measurements were available for $87 \%$ of the patients with DM and $83 \%$ of the patients without DM. Diastolic BP was slightly but statistically significantly lower among patients with DM compared with patients without DM (table 2). For 


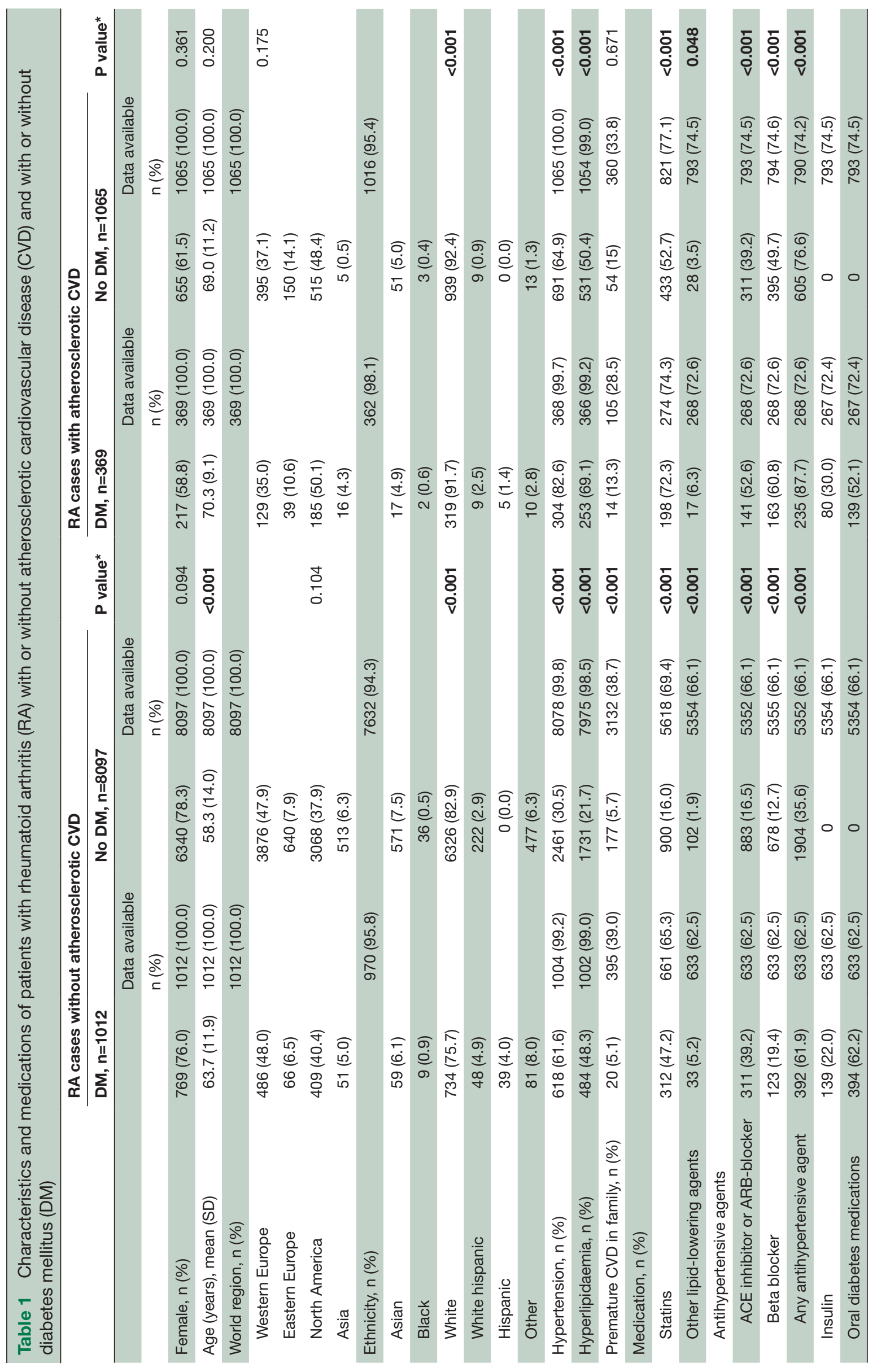

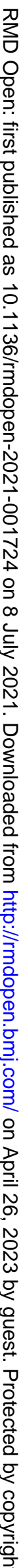




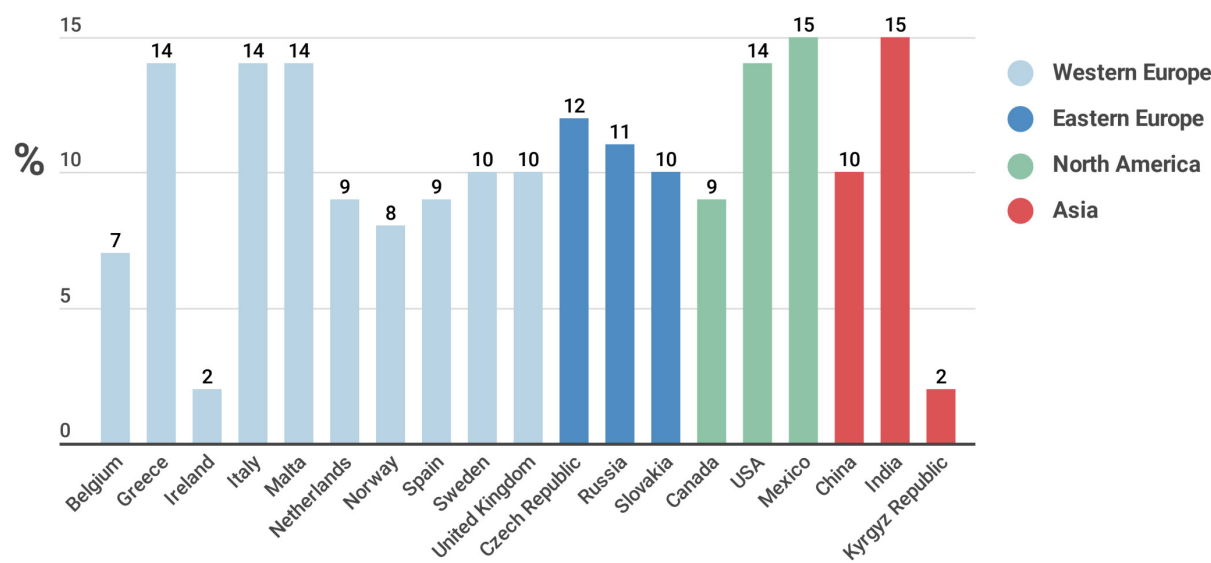

Figure 1 Percentage of patients with RA with concomitant diagnosis of diabetes mellitus by country. The number over the bars are \%. RA, rheumatoid arthritis.

the majority of patients across world regions, systolic BP was under the commonly used treatment target of $140 \mathrm{~mm} \mathrm{Hg}$ (figure 3D). No consistent differences in systolic BP between patients with or without DM were noted.

\section{DISCUSSION}

To our knowledge, this is the first report comparing ASCVD risk factors, prevention and attainment of guidelinerecommended treatment targets in patients with RA with and without DM. The major finding in this audit was that the treatment results for primary and secondary ASCVD prevention were superior in patients with RA with DM compared with patients with RA without DM. This was especially reflected in the higher proportion of patients with RA with ASCVD and DM reaching their lipid goals compared with patients with RA with ASCVD but without DM. Furthermore, screening of many CVD risk factors, especially hypercholesterolemia and DM or pre-diabetes, among patients with RA was inadequate and needs to be improved globally. Our findings highlight the importance of raising awareness of the increased risk of CVD in patients with RA, which can be achieved by information campaigns directed at patients and their spouses and all categories of healthcare personnel.

In this large audit of ASCVD and its risk factors in patients with RA, we have shown that patients with RA with DM have more than two times the frequency of ASCVD compared with patients with RA without DM.

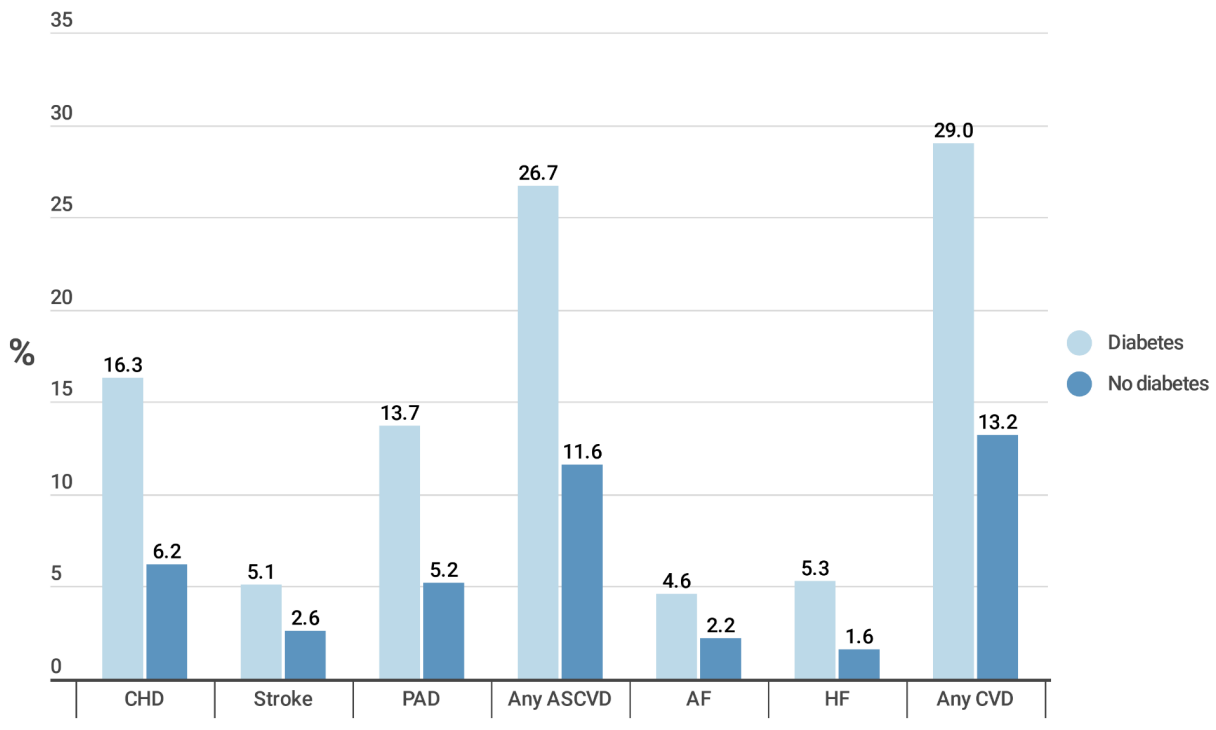

Figure 2 Prevalence of cardiovascular diseases (CVDs) among patients with rheumatoid arthritis with diabetes mellitus $(n=1381)$ and without diabetes mellitus $(n=9162)$. AF, atrial fibrillation; ASCVD, atherosclerotic cardiovascular disease; CHD, coronary heart disease; HF, heart failure; PAD, peripheral artery disease. 


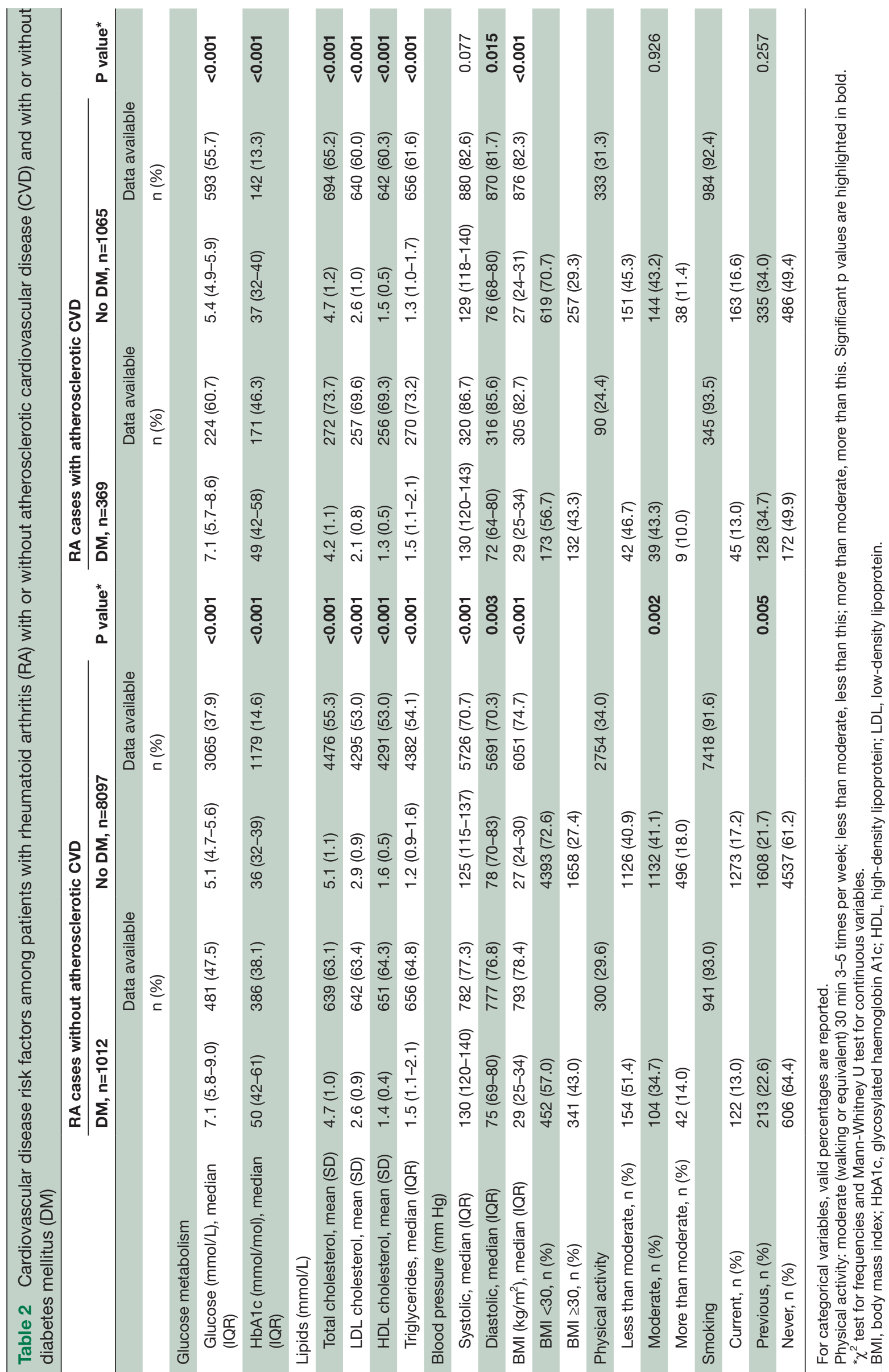

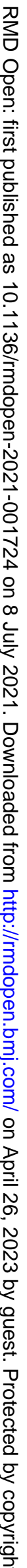


A. LDL-c among RA cases without ASCVD but with lipid-lowering agents

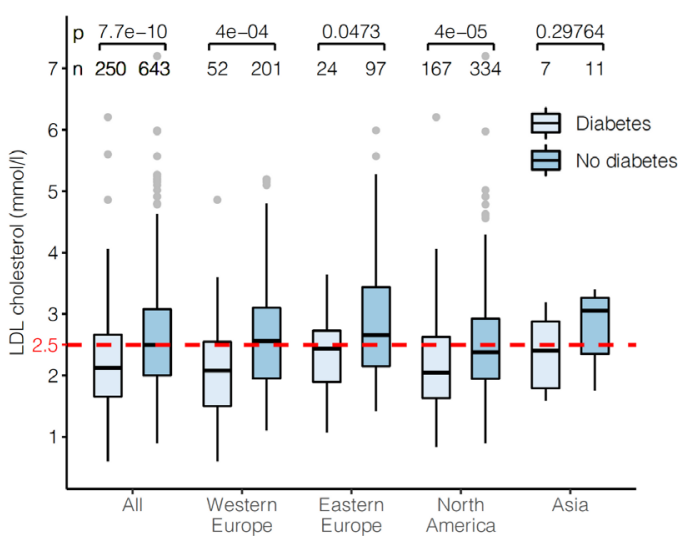

C. Systolic BP among RA cases without ASCVD but with antihypertensive agents

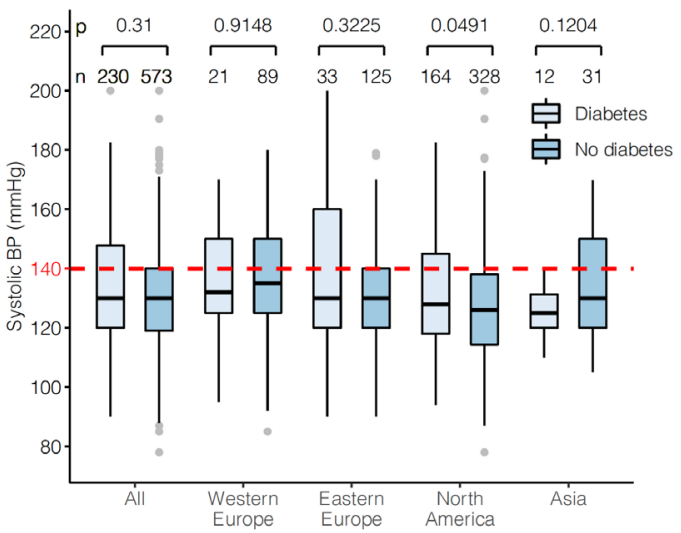

B. LDL-c among RA cases with ASCVD

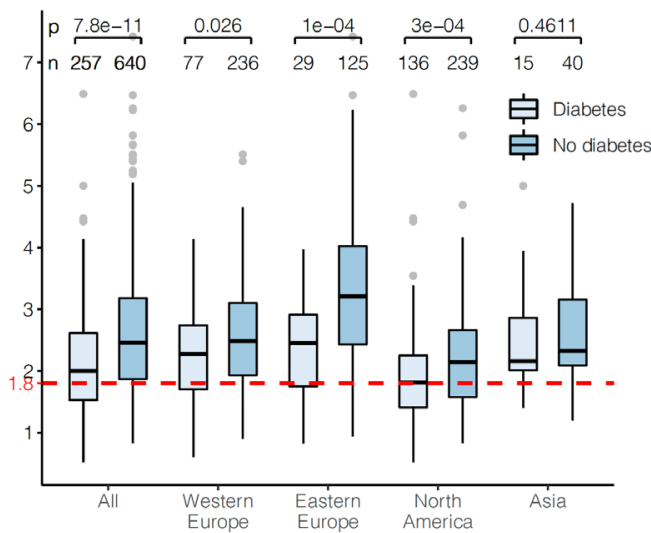

D. Systolic BP among RA cases with ASCVD

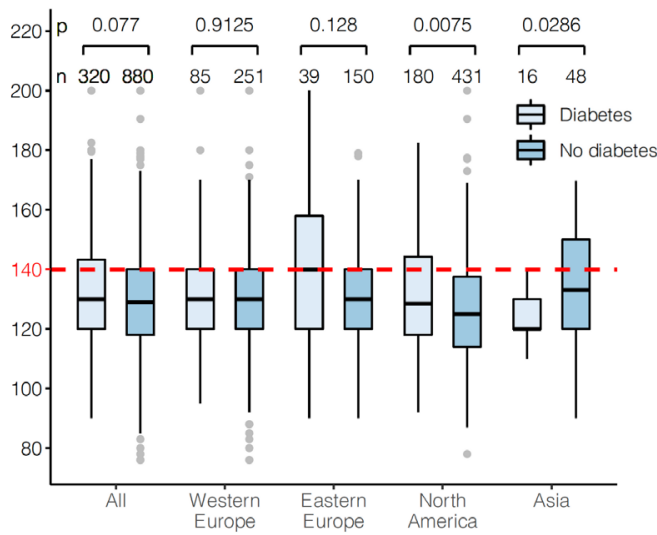

Figure 3 (A-D) Treatment target attainment for LDL-C and systolic BP among patients with RA with or without diabetes in primary prevention and secondary prevention by world regions. (A) LDL-c level in RA cases without ASCVD but with lipidlowering agents for primary prevention. (B) LDL-c level in RA cases with ASCVD and in need of secondary prevention. (C) Systolic BP among patients with RA with antihypertensive drug treatment but no ASCVD. (D) BP among patients with RA with ASCVD. Red dashed lines depict commonly used treatment targets. Differences between patients with or without DM were compared with Mann-Whitney $U$ test. The boxplots represent the distribution of measurements, with median as the black horizontal line in the middle of the box, IQR from 25th (Q1) to 75th (Q3) percentiles as the height of the box, and whiskers as Q1-1.5*IQR and Q3+1.5*IQR. Outliers are represented by grey dots. ASCVD, atherosclerotic cardiovascular disease; BP, blood pressure; DM, diabetes mellitus; LDL-c, low-density lipoprotein cholesterol; RA, rheumatoid arthritis.

The increased risk of myocardial infarction in patients with RA has been known for decades and was reported by Holmqvist $e t$ at to be increased by $40 \%$ compared with the general population, despite the overall reduction in ASCVD since the 1970s. Furthermore, in line with our findings, a Danish nationwide cohort study including patients from 1997 to 2006 has reported a roughly doubled myocardial infarction incidence rate among patients with RA with DM compared with those without. ${ }^{7}$ We point out that our contemporary data imply that this increased ASCVD risk linked to the combination of having both RA and DM has not improved since then.

Despite the knowledge of the increased risk of ASCVD in patients with RA, their CVD risk factors often remain underdiagnosed and they receive poorer CVD prevention than general population. ${ }^{19}{ }^{20} \mathrm{We}$ found that patients with RA with DM more often used lipid-lowering and antihypertensive medications compared with their counterparts without DM, regardless if they had ASCVD or not. This may reflect the well-developed CVD preventive programmes in patients with DM. This patient group has specialised clinics, nurses, information materials and screening routines in many countries, although there may be variations in medical handling of DM across geographical regions. Despite the fact that statins are safe and effective among patients with RA, ${ }^{21}{ }^{22}$ an alarmingly low proportion (roughly 50\%) of patients with RA without DM but with ASCVD used statins, and only a quarter reached the LDL-c target of $\leq 1.8 \mathrm{mmol} / \mathrm{L}$. This could be related to clinical inertia, and warrants attention to initiation and adherence of lipid-lowering treatment. Also among the general population, CVD risk factors are strikingly common, and primary and secondary prevention are often inadequate. ${ }^{23-25}$ A European 18-country observational study of patients using lipid-lowering agents showed that the 2016 LDL goals were attained by only $22 \%$ and $45 \%$ of the very high-risk primary and secondary prevention patients, respectively. ${ }^{23}$ In the EUROASPIRE 
V study across 27 countries, $29 \%$ of patients with CHD reached LDL target of $<1.8 \mathrm{mmol} / \mathrm{L}^{24}$

The prevalence of diagnosed DM in patients with RA across countries varied mostly from $8 \%$ to $15 \%$, although there were a few exceptions with DM prevalence as low as $2 \%$. Our findings are comparable to results from other RA cohorts from Italy $^{15}$ (DM prevalence 13.6\%) and the USA (10.4\%) ${ }^{26}$ However, reflecting poor risk factor monitoring, HbAlc measurements were found in only less than one out of six patients with RA without DM, and thus we speculate that undiagnosed DM may be a considerable problem among patients with RA. Widdifield and colleagues have reported that only half of the individuals with RA were screened for CVD risk factors, including HbA1c. ${ }^{27}$ Importantly, an association between RA and undiagnosed DM has been reported by a German cross-sectional study. ${ }^{28}$ Of note, we found 20 patients without known diabetes but with diabetic HbA1c (range 48.6-58.5 mmol/L, median 49.7), suggesting that HbAlc levels slightly over the diabetic threshold may not always receive attention.

The low frequency of lipid measurements in our survey reflects poor CVD risk factor management. This may be due to insufficient knowledge among health personnel, ${ }^{29}$ and due to diffusion of responsibility for CVD risk evaluation between general practitioners, cardiologists and rheumatologists. The higher lipid goal attainment in patients with RA with DM may be related to the high focus on prevention of microvascular and macrovascular complications beyond glycaemic control in DM care, which is emphasised in DM treatment guidelines ${ }^{3} 3031$ and is well-implemented in primary care settings. Among patients with DM, CVD risk management may be taken care of by primary care physicians, internists or endocrinologists, whereas for patients with RA, CVD risk management is mostly carried out by primary care physicians or rheumatologists. ${ }^{32}$ This may also explain why pharmacological secondary prevention, including lipid-lowering drugs, beta-blockers and ACE-inhibitors/angiotensin receptor blockers, was more frequent among the patients with RA with DM compared with those without. In addition, presence of DM may increase adherence to statins. ${ }^{33}$

The treatment goal of antihypertensive treatment was set at $<140 / 90 \mathrm{~mm} \mathrm{Hg}$ for patients without DM and $<140 / 80 \mathrm{~mm} \mathrm{Hg}$ for patients with DM according to the prevailing guidelines at the time of the survey, which is a modest approach compared with the most recent European guidelines on hypertension, which define different targets depending on age and side effects. ${ }^{34}$ Surprisingly, based on single measurements BP was well controlled in patients with RA. This is in contrast to patients with RA from a US report, where $40 \%$ had BP $>140 / 90 \mathrm{~mm} \mathrm{Hg},{ }^{14}$ and to large populations with established CHD such as in Eurospire V survey ( $42 \%$ had BP $>140 / 90 \mathrm{~mm} \mathrm{Hg}$ ) and in SURF-CHD survey ( $40 \%$ not at BP target)..$^{245}$

There are several limitations of a survey such as SURFRA. First, the variations of the recorded prevalence of ASCVD risk factors across the three world continents may reflect the various settings for such risk factor recording. For example, the risk factors reported from North America were mostly extracted from primary care patient records, while SURF-RA centres in Western Europe were mostly rheumatology outpatient clinics and some cardiology outpatient clinics. Some of the data were extracted from pre-existing registries, which may explain the differences in missing data across the geographic regions. The rates of missing data on CVD risk factors highlight that, even in rheumatology centres with a focus on CVD prevention, the screening and recording of these crucial clinical variables are incomplete. This underlines the importance of increasing the awareness of this clinical field. The centres participating in the audit were either invited through the ATACC-RA network (www.atacc-ra.com) or invited through conference contacts. Therefore, the representativeness of the cohorts in relation to nations, ethnic groups or geographic regions is not complete. In addition, the number of patients included from the various regions differed, with more patients recruited from North America and Western Europe. Another limitation is that we used the treatment goals of European recommendations in evaluating treatment target attainment across world regions. Medication adherence was not evaluated and this may have influenced goal attainment. Participating centres did not share standardised instruments for measurements, for example, same BP monitors, height and weight measuring scales and laboratory measurements. Despite these limitations, clinical audits are valuable tools for improving clinical performance in implementing guideline-recommended procedures.

\section{CONCLUSION}

The use of CVD preventive medications and the presence of ASCVD was higher in patients with RA with DM than in patients with RA without DM. Lipid goals were also more frequently obtained in patients with RA with than without DM in both primary and secondary prevention. Based on this survey, special attention is needed to ensure that patients with RA with ASCVD reach their lipid goals. Data from the SURF-RA indicate that CVD prevention in DM is better implemented compared with patients with $\mathrm{RA}$, and lessons may be drawn from the existing CVD prevention programmes in DM to enhance CVD prevention among patients with RA.

\section{Author affiliations}

${ }^{1}$ Preventive Cardio-Rheuma Clinic, Division of Rheumatology and Research, Diakonhjemmet Hospital, Oslo, Norway

${ }^{2}$ Division of Rheumatology and Research, Diakonhjemmet Hospital, Oslo, Norway ${ }^{3}$ Health Sciences Research, Mayo Clinic Rochester, Rochester, Minnesota, USA

${ }^{4}$ Rheumatology, Radboud University Nijmegen, Nijmegen, The Netherlands

${ }^{5}$ Department of Rheumatology, Dudley Group of Hospitals NHS Trust, Dudley, UK

${ }^{6}$ Cardiology, Trinity College Dublin, Dublin, Ireland

${ }^{7}$ Department of Public Health and Clinical Medicine/Rheumatology, Umeå Universitet Medicinska Fakulteten, Umea, Sweden

${ }^{8}$ Internal Medicine-Rheumatology, Harbor-UCLA Medical Center, Torrance, California, USA 
${ }^{9}$ Division of Rheumatology, Department of Internal Medicine, Mayo Clinic Rochester, Rochester, Minnesota, USA

${ }^{10}$ Rheumatology, Hospital Universitario Marques de Valdecilla, Santander, Spain

${ }^{11}$ First Department of Propaedeutic and Internal Medicine, University of Athens, Athens, Greece

${ }^{12} 2$ nd Department of Medicine and Laboratory, Clinical Immunology-Rheumatology Unit, National and Kapodistrian University of Athens School of Medicine, Athens, Greece

${ }^{13}$ Medicine, Mount Sinai Hospital, Toronto, Ontario, Canada

${ }^{14}$ Rheumatology, University of Manitoba, Winnipeg, Manitoba, Canada

${ }^{15}$ Rheumatology, Université Catholique de Louvain, Louvain-la-Neuve, Belgium

${ }^{16}$ Immunology and Rheumatology, Instituto Nacional de Ciencias Medicas y

Nutricion Salvador Zubiran, Mexico City, Mexico

${ }^{17}$ Rheumatology, Hospital Universitario Dr Jose Eleuterio Gonzalez, Monterrey,

Nuevo León, Mexico

${ }^{18}$ Cardiothoracic, Fondazione Poliambulanza Instituto 0spedaliero, Brescia, Italy

${ }^{19}$ Department of Clinical Immunology and Rheumatology, Sanjay Gandhi Post

Graduate Institute of Medical Sciences, Lucknow, Uttar Pradesh, India

${ }^{20}$ Department of Rheumatology, Mater Dei Hospital, Msida, Malta

${ }^{21}$ Rheumatology, Peking University People's Hospital, Beijing, China

${ }^{22}$ Kyrgyz State Medical Academy Faculty of General Medicine, Bishkek, Kyrgyzstan

${ }^{23}$ Medicine, Tallaght University Hospital, Dublin, Ireland

${ }^{24}$ Rheumatology, Ivanovo State Medical Academy, Ivanovo, Ivanovskaa oblast, Russian Federation

${ }^{25}$ Rheumatology, FSBI National Medical and Surgical Center named after N I

Pirogov of the Ministry of Healthcare of the Russian Federation, Moskva, Russian Federation

${ }^{26}$ V.A. Nasonova Research Institute of Rheumatology, Moscow, Russian Federation

${ }^{27}$ Rheumatology, Narodny Ustav Reumatickych Chorob, Piestany, Slovakia

${ }^{28} 3$ rd Department of Internal Medicine, General University Hospital and 1st Faculty

of Medicine, Charles University, Prague, Czech Republic

${ }^{29}$ Third Department of Internal Medicine, Department of Endocrinology and Metabolism, Charles University First Faculty of Medicine, Praha, Czech Republic

${ }^{30}$ Krajska zdravotni a.s, Masaryk Hospital in Usti nad Labem, Usti nad Labem, Czech Republic

${ }^{31}$ First Medical Faculty, Charles University, Praha, Czech Republic

${ }^{32}$ Department of Internal Medicine III-Nephrology, Rheumatology and Endocrinology, University Hospital Olomouc, Olomouc, Olomoucký, Czech Republic

${ }^{33}$ Division of Rheumatology, 2nd Department of Internal Medicine-Gastroenterology, Charles University First Faculty of Medicine, Hradec Králové, Czech Republic

\section{Twitter Durga Prasanna Misra @DurgaPrasannaM1}

Acknowledgements We are grateful and in debt to all those clinicians and health personnel who have participated in gathering information for the SURF-RA.

Contributors AGS contributed to conception, design, acquisition, analysis, interpretation and drafted including critically revised and gave final approval of the manuscript, AMK and SR contributed to conception and design of the analyses, interpretation, drafted, critically revised and gave final approval of the manuscript, JS contributed to design, acquisition, analysis, interpretation, critically revised and gave final approval of the manuscript, El, GW contributed to conception, acquisition, interpretation, critically revised and gave final approval of the manuscript, IG, PvR, GK, CC contributed to conception, design, interpretation, critically revised and gave final approval of the manuscript, SR-D, GAK, MAG-G, PPS, BK, CH, MSS, VP-R, DAG-D, SM contributed to conception, design, acquisition, interpretation, critically revised and gave final approval of the manuscript, MT, AL, DV, PD, PF, DPM, AAB, RM, EMM, DG, LK, TVP, AT, MT, MV, JL, PH, TS contributed to conception, acquisition, interpretation, critically revised and gave final approval of the manuscript.

Funding The work was supported by grants from the South Eastern Regional Health Authorities of Norway (2013064 for AGS and 2016063 for SR) and FOREUM (the Foundation for Research in Rheumatology for AMK). Further support was through a collaborative agreement for independent research from Eli Lilly who had no role in the study design, data collection and analysis, decision to publish or preparation of the manuscript.

Competing interests None declared.

Patient consent for publication Not required.

Ethics approval This is an audit of quality assurance of data in patient journals. The data were pseudonymised. The SURF-RA study has been approved by the Data Protection Officer (DP0) at the Oslo University Hospital-Ullevaal (2017/7243), and a general data protection regulation evaluation was performed by the DPO at
Diakonhjemmet Hospital (10/10-2018), Oslo, Norway. Following this evaluation, an informed consent from participants was considered not necessary. Each participating centre was responsible for obtaining the correct regulatory approval for participating in SURF-RA.

Provenance and peer review Not commissioned; externally peer reviewed.

Data availability statement No data are available. All data relevant to the study are included in the article or uploaded as supplementary information. The data were pseudonymised by each centre before transferred to the data handling centre at Diakonhjemmet hospital, where it is stored on a central server. The data handling manager is Joe Sexton (joesexton0@gmail.com) and the data centre leader is Anne Grete Semb (a-semb@diakonsyk.no).

Open access This is an open access article distributed in accordance with the Creative Commons Attribution Non Commercial (CC BY-NC 4.0) license, which permits others to distribute, remix, adapt, build upon this work non-commercially, and license their derivative works on different terms, provided the original work is properly cited, appropriate credit is given, any changes made indicated, and the use is non-commercial. See: http://creativecommons.org/licenses/by-nc/4.0/.

\section{ORCID iDs}

Anne Grete Semb http://orcid.org/0000-0003-2730-2853

George Athanasios Karpouzas http://orcid.org/0000-0003-1065-1563

Miguel A Gonzalez-Gay http://orcid.org/0000-0002-7924-7406

Maria G Tektonidou http://orcid.org/0000-0003-2238-0975

Patrick Durez http://orcid.org/0000-0002-7156-2356

Virginia Pascual-Ramos http://orcid.org/0000-0002-7368-498X

Dionicio Angel Galarza-Delgado http://orcid.org/0000-0001-9714-2109

Durga Prasanna Misra http://orcid.org/0000-0002-5035-7396

Vikas Agarwal http://orcid.org/0000-0002-4508-1233

Tatiana Valentinovna Popkova http://orcid.org/0000-0001-5793-4689

\section{REFERENCES}

1 Vardas P, Timmis A. Diabetes. In: Cardiovascular realities 2019 European heart agency (European Society of cardiology, 2019: 26-7.

2 Timmis A, Townsend N, Gale CP, et al. European Society of cardiology: cardiovascular disease statistics 2019. Eur Heart J 2020;41:12-85.

3 Cosentino F, Grant PJ, Aboyans V, et al. 2019 ESC guidelines on diabetes, pre-diabetes, and cardiovascular diseases developed in collaboration with the EASD. Eur Heart $J$ 2020;41:255-323.

4 Semb AG, Ikdahl E, Wibetoe G, et al. Atherosclerotic cardiovascular disease prevention in rheumatoid arthritis. Nat Rev Rheumatol 2020;16:361-79.

5 Avina-Zubieta JA, Thomas J, Sadatsafavi M, et al. Risk of incident cardiovascular events in patients with rheumatoid arthritis: a metaanalysis of observational studies. Ann Rheum Dis 2012;71:1524-9.

6 Holmqvist M, Ljung L, Askling J. Acute coronary syndrome in newonset rheumatoid arthritis: a population-based nationwide cohort study of time trends in risks and excess risks. Ann Rheum Dis 2017;76:1642-7.

7 Lindhardsen J, Ahlehoff $\mathrm{O}$, Gislason $\mathrm{GH}$, et al. The risk of myocardial infarction in rheumatoid arthritis and diabetes mellitus: a Danish nationwide cohort study. Ann Rheum Dis 2011;70:929-34.

8 Agca R, Heslinga SC, Rollefstad S, et al. EULAR recommendations for cardiovascular disease risk management in patients with rheumatoid arthritis and other forms of inflammatory joint disorders: 2015/2016 update. Ann Rheum Dis 2017;76:17-28.

9 Semb AG, Ikdahl E, Sexton J. Survey of cardiovascular disease and risk factor management in patients with rheumatoid arthritis across 5 world regions: results from the SURF-RA. Eur. Heart J 2020;41.

10 Nicolau J, Lequerré T, Bacquet $\mathrm{H}$, et al. Rheumatoid arthritis, insulin resistance, and diabetes. Joint Bone Spine 2017;84:411-6.

11 Jafri K, Bartels CM, Shin D, et al. Incidence and management of cardiovascular risk factors in psoriatic arthritis and rheumatoid arthritis: a population-based study. Arthritis Care Res 2017;69:51-7.

12 Monk HL, Muller S, Mallen CD, et al. Cardiovascular screening in rheumatoid arthritis: a cross-sectional primary care database study. BMC Fam Pract 2013:14:150.

13 Castañeda S, Martín-Martínez MA, González-Juanatey C, et al. Cardiovascular morbidity and associated risk factors in Spanish patients with chronic inflammatory rheumatic diseases attending rheumatology clinics: baseline data of the CARMA project. Semin Arthritis Rheum 2015;44:618-26.

14 Chung CP, Giles JT, Petri M, et al. Prevalence of traditional modifiable cardiovascular risk factors in patients with rheumatoid arthritis: comparison with control subjects from the multi-ethnic study of atherosclerosis. Semin Arthritis Rheum 2012;41:535-44. 
15 Ruscitti P, Ursini F, Cipriani P, et al. Prevalence of type 2 diabetes and impaired fasting glucose in patients affected by rheumatoid arthritis: results from a cross-sectional study. Medicine 2017;96:e7896.

16 Albrecht K, Luque Ramos A, Hoffmann F, et al. High prevalence of diabetes in patients with rheumatoid arthritis: results from a questionnaire survey linked to claims data. Rheumatology 2018;57:329-36.

17 Doran B, Guo Y, Xu J, et al. Prognostic value of fasting versus nonfasting low-density lipoprotein cholesterol levels on long-term mortality: insight from the National health and nutrition examination survey III (NHANES-III). Circulation 2014;130:546-53.

18 Authors/Task Force Members, Piepoli MF, Hoes AW, et al. 2016 European Guidelines on cardiovascular disease prevention in clinical practice: The Sixth Joint Task Force of the European Society of Cardiology and Other Societies on Cardiovascular Disease Prevention in Clinical Practice (constituted by representatives of 10 societies and by invited experts): Developed with the special contribution of the European Association for Cardiovascular Prevention \& Rehabilitation (EACPR). Eur J Prev Cardiol 2016:23:NP1-96.

19 Lindhardsen J, Ahlehoff O, Gislason GH, et al. Initiation and adherence to secondary prevention pharmacotherapy after myocardial infarction in patients with rheumatoid arthritis: a nationwide cohort study. Ann Rheum Dis 2012;71:1496-501.

20 Dougados M, Soubrier M, Antunez A, et al. Prevalence of comorbidities in rheumatoid arthritis and evaluation of their monitoring: results of an international, cross-sectional study (COMORA). Ann Rheum Dis 2014;73:62-8.

21 Semb AG, Kvien TK, DeMicco DA, et al. Effect of intensive lipidlowering therapy on cardiovascular outcome in patients with and those without inflammatory joint disease. Arthritis Rheum 2012;64:2836-46

22 Kitas GD, Nightingale P, Armitage J. Trial of atorvastatin for the primary prevention of cardiovascular events in patients with rheumatoid arthritis (trace RA): a multicenter, randomized, placebo controlled trial. Arthritis Rheum 2019.

23 Ray KK, Molemans B, Schoonen WM, et al. EU-Wide cross-sectional observational study of Lipid-Modifying therapy use in secondary and primary care: the dA Vinci study. Eur J Prev Cardiol 2020:zwaa047.

24 Kotseva K, De Backer G, De Bacquer D, et al. Lifestyle and impact on cardiovascular risk factor control in coronary patients across
27 countries: results from the European Society of cardiology ESC-EORP EUROASPIRE V registry. Eur J Prev Cardiol 2019;26:824-35

25 Jóźwiak JJ, Studziński K, Tomasik T, et al. The prevalence of cardiovascular risk factors and cardiovascular disease among primary care patients in Poland: results from the LIPIDOGRAM2015 study. Atheroscler Suppl 2020;42:e15-24.

26 Han C, Robinson DW, Hackett MV, et al. Cardiovascular disease and risk factors in patients with rheumatoid arthritis, psoriatic arthritis, and ankylosing spondylitis. J Rheumatol 2006;33:2167-72.

27 Widdifield J, Ivers NM, Bernatsky S, et al. Primary care screening and comorbidity management in rheumatoid arthritis in Ontario, Canada. Arthritis Care Res 2017;69:1495-503.

28 Ursini F, Russo E, D'Angelo S, et al. Prevalence of undiagnosed diabetes in rheumatoid arthritis: an OGTT study. Medicine 2016;95:e2552.

29 Bell C, Rowe IF. The recognition and assessment of cardiovascular risk in people with rheumatoid arthritis in primary care: a questionnaire-based study of general practitioners. Musculoskeletal Care 2011;9:69-74.

30 American Diabetes Association. 2. Classification and Diagnosis of Diabetes: Standards of Medical Care in Diabetes-2019. Diabetes Care 2019;42:S13-28.

31 American Diabetes Association. 10. Cardiovascular Disease and Risk Management: Standards of Medical Care in Diabetes-2019. Diabetes Care 2019;42:S103-23.

32 Weijers JM, Semb AG, Rollefstad S, et al. Strategies for implementation of guideline recommended cardiovascular risk management for patients with rheumatoid arthritis: results from a questionnaire survey of expert rheumatology centers. Rheumatol Int 2020;40:523-7.

33 Hope HF, Binkley GM, Fenton S, et al. Systematic review of the predictors of statin adherence for the primary prevention of cardiovascular disease. PLoS One 2019;14:e0201196.

34 Williams B, Mancia G, Spiering W, et al. 2018 ESC/ESH guidelines for the management of arterial hypertension. Eur Heart $J$ 2018;39:3021-104

35 Zhao M, Cooney MT, Klipstein-Grobusch K, et al. Simplifying the audit of risk factor recording and control: a report from an international study in 11 countries. Eur J Prev Cardiol 2016;23:1202-10. 
Correction: Diabetes mellitus and cardiovascular risk management in patients with rheumatoid arthritis: an international audit

Semb AG, Rollefstad S, Ikdahl E, et al. SURF-RA collaborators. Diabetes mellitus and cardiovascular risk management in patients with rheumatoid arthritis: an international audit. RMD Open 2021;7:e001724. doi:10.1136/rmdopen-2021-001724

The published version misspelled co-author's name as Maria G G Tektonidou. The correct name should be Maria G Tektonidou.

Open access This is an open access article distributed in accordance with the Creative Commons Attribution Non Commercial (CC BY-NC 4.0) license, which permits others to distribute, remix, adapt, build upon this work noncommercially, and license their derivative works on different terms, provided the original work is properly cited, appropriate credit is given, any changes made indicated, and the use is non-commercial. See: http://creativecommons. org/licenses/by-nc/4.0/.

(C) Author(s) (or their employer(s)) 2021. Re-use permitted under CC BY-NC. No commercial re-use. See rights and permissions. Published by BMJ.

RMD Open 2021;7:e001724corr1. doi:10.1136/rmdopen-2021-001724corr1

Check for updates 